\title{
Effects of Fat on Insulin-stimulated Carbohydrate Metabolism in Normal Men
}

G. Boden, F. Jadali, J. White, ${ }^{\star}$ Y. Liang, ${ }^{\ddagger}$ M. Mozzoli, X. Chen, E. Coleman, and C. Smith"

Division of Endocrinology/Metabolism and General Clinical Research Center, Departments of Surgery* and Biochemistry, ${ }^{8}$ Temple

University School of Medicine, and Diabetes Research Center, University of Pennsylvania, ${ }^{\ddagger}$ Philadelphia, Pennsylvania 19140

\begin{abstract}
We have examined the onset and duration of the inhibitory effect of an intravenous infusion of lipid/heparin on total body carbohydrate and fat oxidation (by indirect calorimetry) and on glucose disappearance (with 6,6 $\mathrm{D}_{\mathbf{2}}$-glucose and gas chromatography-mass spectrometry) in healthy men during euglycemic hyperinsulinemia. Glycogen synthase activity and concentrations of acetyl-CoA, free CoA-SH, citrate, and glucose-6-phosphate were measured in muscle biopsies obtained before and after insulin/lipid and insulin/saline infusions. Lipid increased insulin-inhibited fat oxidation $(+\mathbf{4 0 \%})$ and decreased insulinstimulated carbohydrate oxidation $(-63 \%)$ within $1 \mathrm{~h}$. These changes were associated with an increase $(+489 \%)$ in the muscle acetyl-CoA/free CoA-SH ratio. Glucose disappearance did not decrease until $2-4 \mathrm{~h}$ later $(-55 \%)$. This decrease was associated with a decrease in muscle glycogen synthase fractional velocity $(-82 \%)$. The muscle content of citrate and glucose-6phosphate did not change. We concluded that, during hyperinsulinemia, lipid promptly replaced carbohydrate as fuel for oxidation in muscle and hours later inhibited glucose uptake, presumably by interfering with muscle glycogen formation. ( $J$. Clin. Invest. 1991. 88:960-966.) Key words: acetyl-coenzyme • carbohydrate oxidation $\bullet$ carbohydrate storage $\bullet$ citrate $\bullet$ muscle glycogen synthase
\end{abstract}

\section{Introduction}

More than 25 years ago Randle et al. (1) demonstrated that increased availability of fatty acids enhanced fat oxidation (FAT OX) ${ }^{1}$ and decreased carbohydrate oxidation (CHO OX) and glucose uptake in perfused rat heart and to a lesser extent in rat diaphragm. Based on these findings, they proposed a glucose-fatty acid cycle presumed to be of fundamental importance for the control of blood glucose and free fatty acid (FFA) concentrations and insulin sensitivity (1). Inasmuch as FFA

Address reprint requests to Dr. Boden, Temple University Hospital, 3401 North Broad Street, Philadelphia, PA 19140.

Received for publication 10 December 1990 and in revised form 29 May 1991.

1. Abbreviations used in this paper: $\mathrm{CHO} O \mathrm{OX}$ and $\mathrm{CHO} S \mathrm{STOR}$, carbohydrate oxidation and storage, respectively; FAT OX, fat oxidation; $G_{R a}$ and $G_{R d}$, rate of glucose appearance and disappearance, respectively; GIR, glucose infusion rates; GS, glucogen synthase; G-6-P, glucose-6-phosphate; NIDDM, non-insulin-dependent diabetes mellitus; $\mathrm{npRQ}$, non-protein respiratory quotient.

J. Clin. Invest.

(c) The American Society for Clinical Investigation, Inc.

0021-9738/91/09/0960/07 \$2.00

Volume 88, September 1991, 960-966 were known to be frequently elevated in obesity and non-insulin-dependent diabetes mellitus (NIDDM), they also postulated that increased FAT OX contributed to the impaired glucose tolerance commonly associated with these conditions (2, 3). Subsequently, many (4-7), but not all (8), investigators were unable to reproduce the fatty acid-mediated inhibition of glucose uptake in rat diaphragm and striated muscle that Randle et al. had observed in perfused rat hearts. (Effects of fatty acids on CHO OX were not examined in these studies.) More recently, several groups (9-17) have examined glucose-fatty acid interactions in vivo during hyperinsulinemia, when most of the glucose uptake occurs in muscle (18). Practically all found that raising FFA increased FAT OX and decreased CHO OX. Some also found inhibitory effects of lipid on glucose uptake $(11,16)$ but most did not $(12,14,15,17)$. Thus, although there seems to be growing acceptance of the idea that increasing FAT OX will reduce $\mathrm{CHO} O \mathrm{OX}$, at least in vivo and under hyperinsulinemic conditions, there remains much controversy as to whether fatty acids also inhibit glucose uptake. Contributing to this uncertainty is the fact that none of the critical enzyme and substrate changes predicted by the glucose-fatty acid cycle to occur in response to increased FAT OX have been demonstrated in human muscle. Furthermore, it is not known whether the time of onset and the duration of the fatty acid-induced alterations are the same or are different for CHO OX and glucose uptake. Noteworthy in this respect are recent findings by Bonnadonna et al. (15), who suggested that the fatty acid effects depended on the time of the fat infusion.

In the present study we have therefore investigated the onset and duration of the inhibitory effect of intravascular lipolysis, produced by intravenous infusion of triglycerides and heparin, on total body $\mathrm{CHO}$ OX and glucose disappearance rates $\left(G_{R d}\right)$ in normal men during euglycemic hyperinsulinemia. In addition, we have obtained muscle biopsies from these individuals before and after lipid and saline infusions for measurement of glycogen synthase (GS) activity and of several important intermediates of fat and CHO metabolism.

\section{Methods}

\section{Subjects}

18 healthy, normal weight men were studied. Their ages, weights, and heights are shown in Table I. None of the subjects had a family history of diabetes or other endocrine disorders and none were taking any medications. Their weights were stable for at least $2 \mathrm{mo}$ and their diets contained a minimum of $250 \mathrm{~g} /$ day of carbohydrates for at least $2 \mathrm{~d}$ before the men were studied. Informed written consent was obtained from all after explanation of the nature, purpose, and potential risks of each study. The study protocol was approved by the Institutional Review Board for Human Research of Temple University. Studies were performed in the General Clinical Research Center of Temple University Hospital and began between 8 and 9 a.m. after an overnight fast. The subjects were studied reclining in bed. A short polyethylene catheter was inserted into an antecubital vein for infusion of all test sub- 
Table I. Study Subjects

\begin{tabular}{cccc}
\hline Study & Age & Weight & Height \\
\hline & $y r$ & $k g$ & $\mathrm{~cm}$ \\
$1(n=6)$ & $26.0 \pm 1.2$ & $79.4 \pm 4.4$ & $180.3 \pm 3.1$ \\
$2(n=6)$ & $25.2 \pm 1.5$ & $82.6 \pm 5.0$ & $181.8 \pm 2.7$ \\
$3(n=6)$ & $26.2 \pm 1.8$ & $82.5 \pm 3.0$ & $181.5 \pm 3.1$ \\
\hline
\end{tabular}

stances. Another catheter was placed into a forearm vein of the same arm to supply the Biostator (Ames Lifescience Instruments, Elkhart, IN) with a continuous flow $(2 \mathrm{ml} / \mathrm{h})$ of blood. A third catheter was inserted into a contralateral forearm vein for blood sampling. This arm was kept at $70^{\circ} \mathrm{C}$ with a heating blanket to arterialize venous blood.

\section{Experimental design}

Study 1. Six subjects were studied. 6,6 $\mathrm{D}_{2}$-glucose (Tracer Technologies, Somerville, MA) was infused i.v. for $7 \mathrm{~h}$ ( -60 to $360 \mathrm{~min}$ ) starting with a bolus of $30 \mu \mathrm{mol} / \mathrm{kg}$ followed by a continuous infusion of 0.3 $\mu \mathrm{mol} / \mathrm{kg} \cdot \mathrm{min}$. At $0 \mathrm{~min}, \mathrm{LIPOSYN}$ II (Abbott Laboratories, North Chicago, IL), a $20 \%$ triglyceride emulsion ( $10 \%$ safflower, $10 \%$ soy bean oil, and $2.14 \mathrm{~g}$ of glycerol per $100 \mathrm{ml})$ plus heparin $(0.4 \mathrm{U} / \mathrm{kg} \mathrm{min})$ were infused at a rate of $1.5 \mathrm{ml} / \mathrm{min}$ for $6.5 \mathrm{~h}$. Regular human insulin (Humulin R, Eli Lilly \& Co., Indianapolis, IN) was infused i.v. at a rate of 1 $\mathrm{mU} / \mathrm{kg} \mathrm{min}$ for $6.5 \mathrm{~h}$ starting at $0 \mathrm{~min}$. Glucose concentrations were clamped at $\sim 85 \mathrm{mg} / \mathrm{dl}$ by a feedback-controlled glucose infusion (Biostator). The first muscle biopsy was performed before the start of the infusions (between -90 and $-60 \mathrm{~min}$ ); a second biopsy was obtained at the end of the studies (between 360 and $390 \mathrm{~min}$ ).

Study 2. Six subjects were studied. The protocol for study 2 was identical to that of study 1 except that saline $(1.5 \mathrm{ml} / \mathrm{min}$ for $6.5 \mathrm{~h})$ was infused instead of lipid/heparin.

Study 3. Six subjects were studied. Infusions of $6,6 \mathrm{D}_{2}$-glucose and insulin were as in study 1 . Lipid/heparin was infused for $2 \mathrm{~h}$ starting at $0 \mathrm{~min}$ at a rate of $1.5 \mathrm{ml} / \mathrm{min}$. At $120 \mathrm{~min}$ the lipid/heparin infusion was discontinued and saline was infused for another $4 \mathrm{~h}$.

\section{Glucose turnover}

Glucose turnover was determined with $6,6 \mathrm{D}_{2}$-glucose. Plasma glucose was isolated from blood drawn at 30-min intervals for determination of isotope enrichment as described (19) with a gas chromatograph-mass spectrometer (model 4610-B, Finnigan-MAT, San Jose, CA). The penta-acetyl derivative of glucose was measured by the electron impact mode at $70 \mathrm{eV}$. Ions were measured at $m / e 242$ and 244 , respectively. Rates of glucose appearance $\left(G_{R_{a}}\right)$ and disappearance $\left(G_{R d}\right)$ were calculated from the isotope enrichment for 30-min intervals using Steele's equation for non-steady-state conditions (20). In all three studies, $G_{R a}$ during hyperinsulinemia were frequently lower than glucose infusion rates (GIR) resulting in negative values for hepatic glucose production. This problem has recently been attributed to errors in Steele's nonsteady-state equation (21). We have assumed that endogenous glucose production was completely suppressed whenever the isotopically determined $G_{R a}$ was equal or smaller than GIR.

Rates of CHO storage (CHO STOR) were obtained by subtracting rates of CHO OX (see below) from $\mathrm{G}_{\mathrm{Rd}}$.

\section{Indirect calorimetry}

Respiratory gas exchange rates were determined as previously described before and at 30-min intervals during lipid/heparin or saline infusions with a metabolic measurement cart (Beckman Instruments, Inc., Palo Alto, CA) (22). Rates of protein oxidation were estimated from urinary nitrogen excretion after correction for changes in urea nitrogen pool size (23). Rates of protein oxidation were used to determine the non-protein respiratory quotient (npRQ). It was assumed that for each gram of $\mathrm{N}$ excreted in the urine, 6.02 liters of $\mathrm{O}_{2}$ were consumed and 4.75 liters of $\mathrm{CO}_{2}$ were produced $(\mathrm{RQ}=0.79)$. Rates of CHO OX and FAT OX were determined with the npRQ tables of Lusk, which are based on an npRQ of 0.707 for $100 \%$ FAT OX and 1.00 for $100 \%$ CHO OX.

\section{Muscle biopsies and extractions}

Biopsies were obtained from the lateral aspect of the vastus lateralis muscle $\sim 15 \mathrm{~cm}$ above the patella from six of six subjects in study 1 and from four of six subjects in study 2 . The skin was cleaned with betadine and anesthetized with $1 \%$ lidocaine without epinephrine in a field block pattern (at $2 \times 3$ in.). (We have found that injection of lidocaine too close to the biopsy site interfered with the measurement of acetyl-CoA.) After an incision ( 1 in.) was made through the skin, subcutaneous tissue, and fascia, $\sim 150 \mathrm{mg}$ of muscle was mobilized and excised. The muscle was dropped immediately into isopentane, kept at its freezing point $\left(-160^{\circ} \mathrm{C}\right)$ by liquid nitrogen. The frozen muscle was stored at $-70^{\circ}$ until it was aliquoted into three separate portions. One portion was extracted with fluoride buffer according to Hagg et al. (24) for measurement of glycogen synthase. A second portion was extracted with perchloric acid according to Allred and Guy (25) for measurement of glucose- 6 phosphate (G-6-P) and citrate. The third portion was extracted with methanol-TCA for measurement of acetyl$\mathrm{CoA}$ and free CoA-SH.

\section{GS assay}

GS was assayed by a modification of the method of Thomas et al. (26). Reactions were started by addition of 30- $\mu$ l aliquots of the muscle extract to $60 \mu \mathrm{l}$ of a reaction mixture containing $20 \mathrm{mM}$ EDTA, $25 \mathrm{mM}$ sodium fluoride, $50 \mathrm{mM}$ Tris-HCl, $1 \%$ glycogen, $0.7 \mu \mathrm{Ci}\left[\mathrm{U}-{ }^{14} \mathrm{C}\right] \mathrm{UDP}$ glucose, $0.3 \mathrm{mM}$ UDP glucose, and 0-10 mM G-6-P. The reaction was terminated after $15 \mathrm{~min}$ by precipitating $75-\mu \mathrm{l}$ aliquots of the reaction mixture on $2 \times 2-\mathrm{cm}$ squares of filter paper which were dropped into cold $66 \%$ ethanol, washed, dried, and counted. GS activity was calculated as micromoles of UDP glucose incorporated into glycogen per minute per milligram of protein. Results are expressed as the fractional velocity of GS activity, i.e., the activity of GS at $0.1 \mathrm{mM} \mathrm{G-6-P} \mathrm{divided}$ by the activity at $10 \mathrm{mM} \mathrm{G-6-P}$. This is an indicator of the active form of GS and believed to be a sensitive parameter of in vivo GS activity (27).

\section{Metabolite assays}

HPLC analysis of Acetyl-CoA and free COA-SH. Frozen muscle samples were minced in $200-400 \mu \mathrm{l}$ of methanol-TCA $(10 \%)$ at $-20^{\circ} \mathrm{C}$ After 5 min at $-20^{\circ} \mathrm{C}, 10$ volumes of ice cold $10 \%$ TCA in $\mathrm{H}_{2} \mathrm{O}$ was added to the sample, followed by sonication in ice for $1 \mathrm{~min}$. The supernatant of the TCA extract was washed five times with ether, which raised the $\mathrm{pH}$ to $\sim 5.0(28)$. The acid-free extract was then lyophilized and stored at $-20^{\circ} \mathrm{C}$ until analysis. HPLC analysis was performed as described (29) using a Waters Associates (Milford, MA) Nova-Pak C18 $5-\mu \mathrm{m}$ reverse-phase column. The two mobile-phase solvents were 0.1 $\mathrm{M} \mathrm{KH}_{2} \mathrm{PO}_{4}$ (A) and $0.1 \mathrm{M} \mathrm{KH}_{2} \mathrm{PO}_{4}$ containing $40 \%$ acetonitrile (B), both at pH 5.0. Acetyl-CoA and free CoA-SH were determined at $260 \mathrm{~nm}$.

Citrate was assayed in a coupled end-point assay with citrate lyase and malate dehydrogenase (30). G-6-P was assayed in a coupled endpoint assay with hexokinase and G-6-P dehydrogenase (31).

\section{Analytical procedures}

Plasma glucose was measured with a glucose analyzer (Beckman Instruments, Inc., Palo Alto, CA). Serum insulin (32) was determined by radioimmunoassay. Blood urea nitrogen (33), was measured colorimetrically. Urinary nitrogen was measured by the method of Kjeldahl (34). Lactate (35) and pyruvate (36) were measured enzymatically.

\section{Statistical analysis and calculations}

All data were expressed as the mean \pm SEM. Statistical significance was assessed using MANOVA and Student's two-tailed paired or unpaired $t$ test. 


\section{Results}

Insulin, glucose, and GIR (Fig. 1)

In all three studies, serum insulin was raised about eightfold from $7.5 \pm 1.0$ to a mean of $58 \pm 5 \mu \mathrm{U} / \mathrm{ml}$ by infusion of insulin $(1 \mathrm{mU} / \mathrm{kg} \cdot \mathrm{min})$. Plasma glucose was clamped at $88 \pm 2 \mathrm{mg} / \mathrm{dl}$ (CV 11.2\%). For the first $3 \mathrm{~h}$ of insulin infusion, GIR were comparable during insulin/saline or insulin/lipid infusions. The inhibitory effect of lipid became statistically significant at $210 \mathrm{~min}$ when GIR had risen to $6.3 \pm 0.4 \mathrm{mg} / \mathrm{kg} \cdot \mathrm{min}$ with saline, while remaining at $3.7 \pm 0.5 \mathrm{mg} / \mathrm{kg} \cdot \mathrm{min}$ with lipid $(P$ $<0.05$ ). When lipid was replaced by saline at $120 \mathrm{~min}$ in study 3, $3 \mathrm{~h}$ elapsed before the inhibitory effect of lipid disappeared and GIR increased significantly.
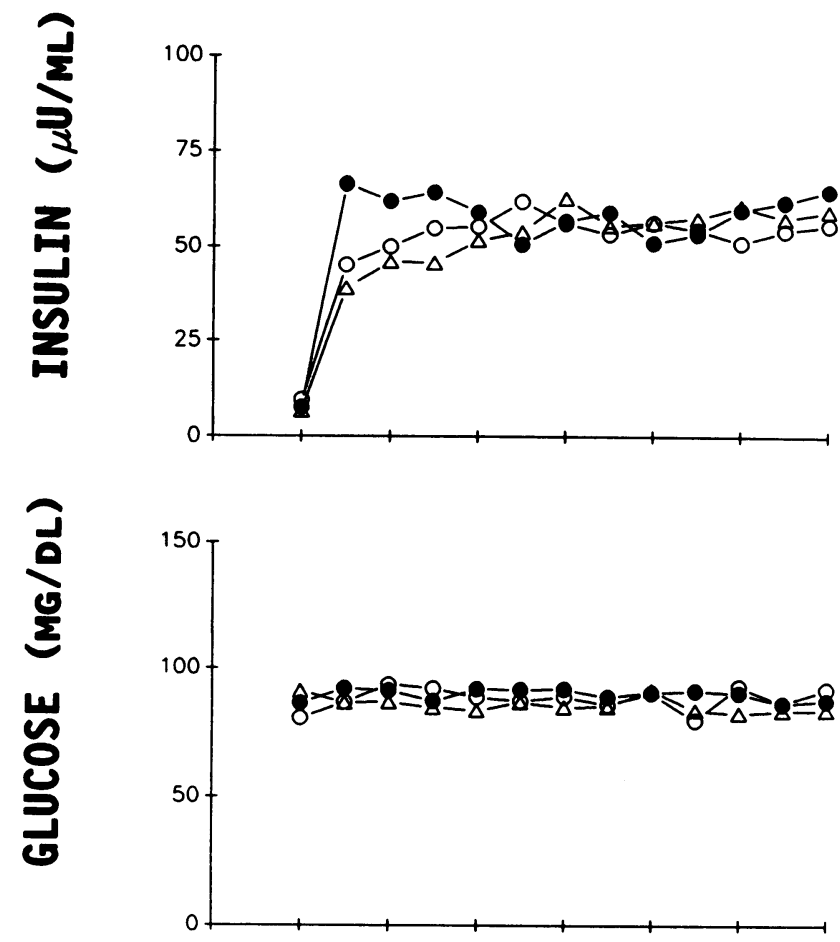

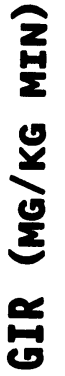

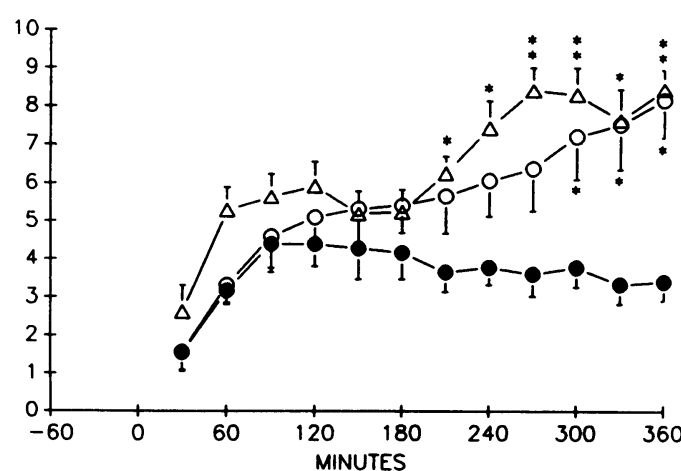

Figure 1. Peripheral venous insulin and glucose concentrations and (GIR) in healthy men during study 1 (lipid infusion during euglycemic hyperinsulinemia, $\bullet, n=6$ ), study 2 (saline infusion during euglycemic hyperinsulinemia, $\Delta, n=6$ ), and study 3 (euglycemic hyperinsulinemia plus lipid from 0 to $2 \mathrm{~h}$ and saline from 2 to $4 \mathrm{~h}, \mathrm{O}, n=6$ ). ${ }^{*} P<0.05,{ }^{* *} P<0.01$ comparing studies 2 with 1 and 3 with 1 .
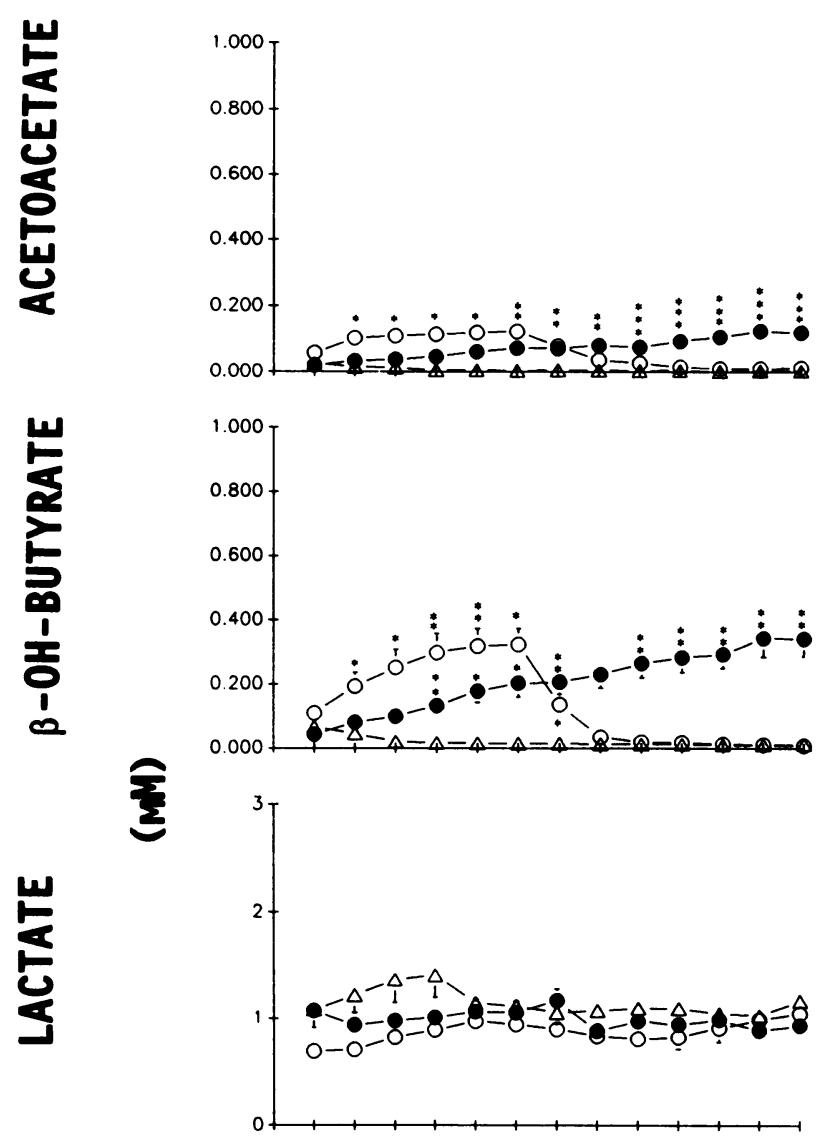

崖

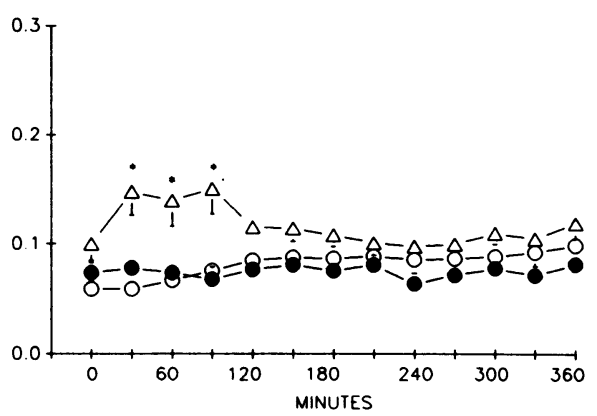

Figure 2. Acetoacetate, $\beta$-OH-butyrate, lactate, and pyruvate concentrations in studies 1-3. In study 1 , lipid/heparin was infused from 0 to $360 \mathrm{~min}$. In study 2 , saline was infused from 0 to $360 \mathrm{~min}$. In study 3 , lipid/heparin was infused from 0 to $120 \mathrm{~min}$ and saline from 120 to $360 \mathrm{~min}$. Symbols and numbers of experiments as in Fig. 1. All studies were performed under euglycemic hyperinsulinemic conditions. Mean \pm SE. ${ }^{*} P<0.05, * * P<0.05,{ }^{* * *} P<0.005$ comparing studies 1 with 2 and 3 with 2.

Ketone bodies, lactate, and pyruvate (Fig. 2)

Insulin/lipid infusion in study 1 resulted in small increases in plasma concentrations of acetoacetate (from 0.02 to $0.12 \mathrm{mM}$, $P<0.001$ ) and $\beta$-hydroxybutyrate (from 0.04 to $0.34 \mathrm{mM}, P$ $<0.001$ ). The accumulation of ketone bodies observed during studies 1 and 3 were, however, too small to affect the calculated rates of CHO OX and FAT OX. After lipid was replaced by saline at $120 \mathrm{~min}$ in study 3 , both ketone bodies returned to basal levels within $1 \mathrm{~h}$. Insulin/saline or insulin/lipid infusions had no effect on plasma lactate and lactate/pyruvate ratios (not 
shown). Pyruvate concentrations were slightly higher during insulin/saline as compared to insulin/lipid infusions between 30 and $90 \min (P<0.05)$.

Onset and duration of effect of lipid on FAT OX, and CHO OX (Fig. 3)

Panel 1. During insulin/lipid infusion, FAT OX rose from $0.63 \pm 0.13 \mathrm{mg} / \mathrm{kg} \cdot \min$ at $0 \mathrm{~min}$ to $0.91 \pm 0.1 \mathrm{mg} / \mathrm{kg} \cdot \min$ at 60 $\min (P<0.05)$ and continued to rise to $1.36 \pm 0.12 \mathrm{mg} / \mathrm{kg} \cdot \min$ at $360 \mathrm{~min}$. During insulin/saline infusion, FAT OX decreased from $0.70 \pm 0.28 \mathrm{mg} / \mathrm{kg} \cdot \mathrm{min}$ at $0 \mathrm{~min}$ to $0.40 \pm 0.23 \mathrm{mg} /$ $\mathrm{kg} \cdot \mathrm{min}$ at $360 \mathrm{~min}$. After lipid was replaced by saline in study 3 , FAT OX fell significantly within $30 \mathrm{~min}$ from $1.3 \pm 0.18$ (at $120 \mathrm{~min}$ ) to $0.93 \pm 0.08 \mathrm{mg} / \mathrm{kg} \cdot \min ($ at $150 \mathrm{~min})(P<0.05)$ and then continued to fall to reach $0.39 \pm 0.14 \mathrm{mg} / \mathrm{kg} \cdot \mathrm{min}$ at $360 \mathrm{~min}$.

Panel 2. During insulin/saline CHO OX increased from $0.85 \pm 0.5(0 \mathrm{~min})$ to $1.93 \pm 0.14 \mathrm{mg} / \mathrm{kg} \cdot \mathrm{min} 30 \mathrm{~min}$ later and then continued to rise to reach $3.15 \pm 0.33 \mathrm{mg} / \mathrm{kg} \cdot \mathrm{min}$ at 360 min. During insulin/lipid infusion CHO OX decreased slowly
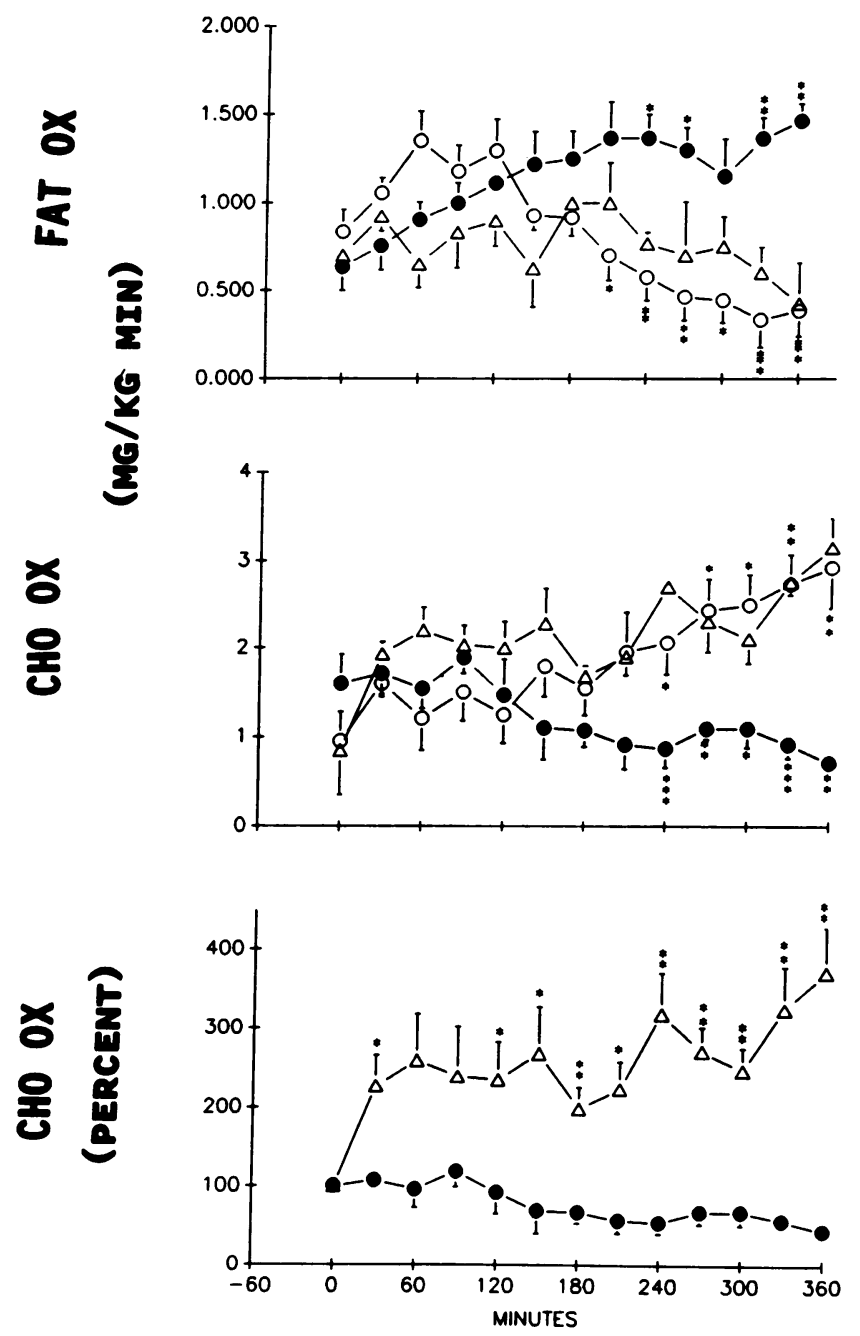

Figure 3. Rates of FAT OX and CHO OX in healthy men during lipid or saline infusions. Symbols and number of experiments were as in Fig. 1 . In the bottom panel, $\mathrm{CHO}$ OX was normalized by setting 0 min values as $100 \%$. Shown are mean \pm SE. ${ }^{*} P<0.05,{ }^{* *} P<0.01$, ${ }^{* * *} P<0.005$ comparing studies 1 with 2 and 3 with 1 . from $1.6 \pm 0.33(0 \mathrm{~min})$ to $0.71 \pm 0.06 \mathrm{mg} / \mathrm{kg} \cdot \min (360 \mathrm{~min})$. After lipid was replaced by saline in study 3, CHO OX increased within $60 \mathrm{~min}$ to values indistinguishable from those seen during insulin/saline infusions.

Panel 3. To better illustrate these directional changes, $\mathrm{CHO}$ OX was normalized with basal values $(0 \mathrm{~min})$ being set at $100 \%$. As can be seen, the difference between insulin/lipid and insulin/saline infusions became statistically significant at $30 \mathrm{~min}$.

Onset and duration of lipid on glucose uptake $\left(G_{R d}\right)$ (Fig. 4) In contrast to its early effect on $\mathrm{CHO} O \mathrm{OX}$, insulin/lipid infusion had no effect on $G_{R d}$ or $G_{R a}$ for at least $3 h$. After $3 h, G_{R d}$ and $G_{R d}$ plateaued at $\sim 4 \mathrm{mg} / \mathrm{kg} \cdot \min$ during insulin/lipid, whereas it continued to rise to between 7 and $8 \mathrm{mg} / \mathrm{kg} \cdot \min$ during insulin/saline infusion. The difference between insulin/ lipid and insulin/saline infusions, however, did not become statistically significant until $330 \mathrm{~min}$. Similarly, after lipid was replaced by saline in study $3, G_{R d}$ and $G_{R d}$ remained inhibited for $3 \mathrm{~h}$ before rising.

Correlations between $G_{R d}, F A T O X$, and CHO OX

$\mathrm{G}_{\mathrm{Rd}}$ did not correlate with FAT OX $(r=-0.19, P<0.04)$ and correlated only weakly with CHO OX $(r=41, P<0.0001)$.

$G S$, acetyl-CoA, free CoA-SH, G-6-P, and citrate in muscle biopsies (Fig. 5)

GS activity, expressed as fractional velocity, i.e., GS activity at a subsaturating $(0.1 \mathrm{mM})$ G-6-P concentration divided by $\mathrm{GS}$

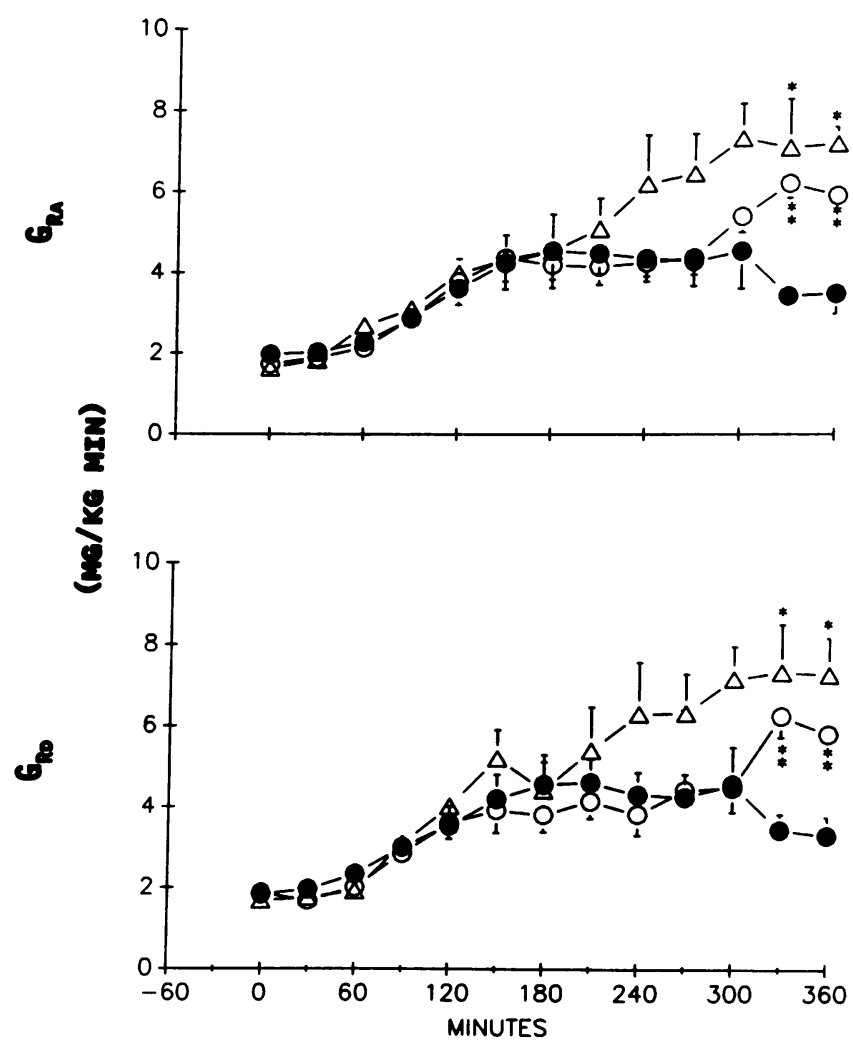

Figure 4. $G_{R a}$ and $G_{R d}$ in healthy men during lipid or saline infusions. Symbols and number of experiments were as in Fig. 1. Shown are mean \pm SE. ${ }^{*} P<0.05,{ }^{* *} P<0.01$ comparing studies 2 with 1 and 3 with 1. 

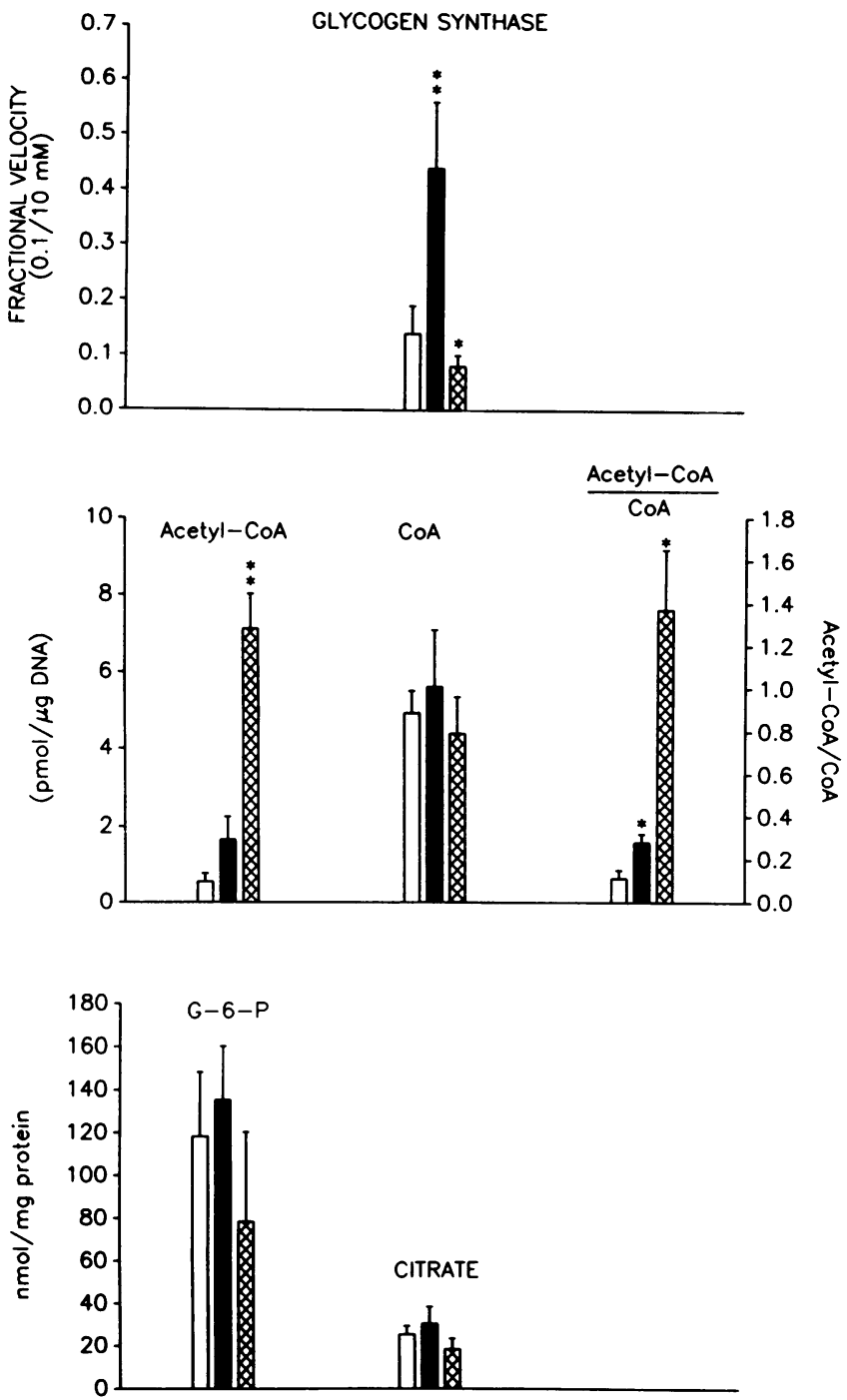

Figure 5. Upper panel: glycogen synthase activity in muscle biopsies expressed as fractional velocity (activity at $0.1 \mathrm{mM}$ G-6-P divided by activity at $10 \mathrm{mM} \mathrm{G-6-P)} \mathrm{before} \mathrm{infusions} \mathrm{(open} \mathrm{bars,} n=10$ ), after $6 \mathrm{~h}$ of euglycemic hyperinsulinemia (solid bars, $n=4$ ) and after $6 \mathrm{~h}$ of lipid plus euglycemic hyperinsulinemia (cross-hatched bars, $n=6$ ). Middle panel: acetyl-CoA and free CoA-SH and the acetyl-CoA/free CoA-SH ratio in muscle biopsies. Symbols and number of experiments as in the upper panel. Lower panel: G-6-P and citrate concentrations in muscle biopsies. Mean \pm SE. ${ }^{*} P<0.05,{ }^{* *} P<0.005 \mathrm{com}$ parison with the preceding column.

activity at a saturating ( $10 \mathrm{mM})$ concentration of G-6-P, increased from $0.14 \pm 0.05$ before to $0.44 \pm 0.12$ after insulin/saline infusion (study 2) $(P<0.02)$. After insulin/lipid infusion (study 1) GS fractional velocity was $0.08 \pm 0.02$; i.e., it failed to rise in response to insulin. GS fractional velocity correlated positively with $\mathrm{G}_{\mathrm{Rd}}(r=0.61)$ (Fig. 6).

Acetyl-CoA concentration was $1.65 \pm 0.6 \mathrm{pmol} / \mu \mathrm{g}$ DNA after insulin/saline and $7.12 \pm 0.90 \mathrm{pmol} / \mu \mathrm{g}$ DNA after insulin/ lipid infusion $(+432 \%, P<0.03)$ whereas the acetyl-CoA/free CoA-SH ratio was $0.28 \pm 0.04$ during insulin/saline and $1.37 \pm 0.28$ during insulin/lipid $(+489 \%, P<0.03)$.

Insulin/saline or insulin/lipid infusions had no significant effects on G-6-P or on citrate concentrations.

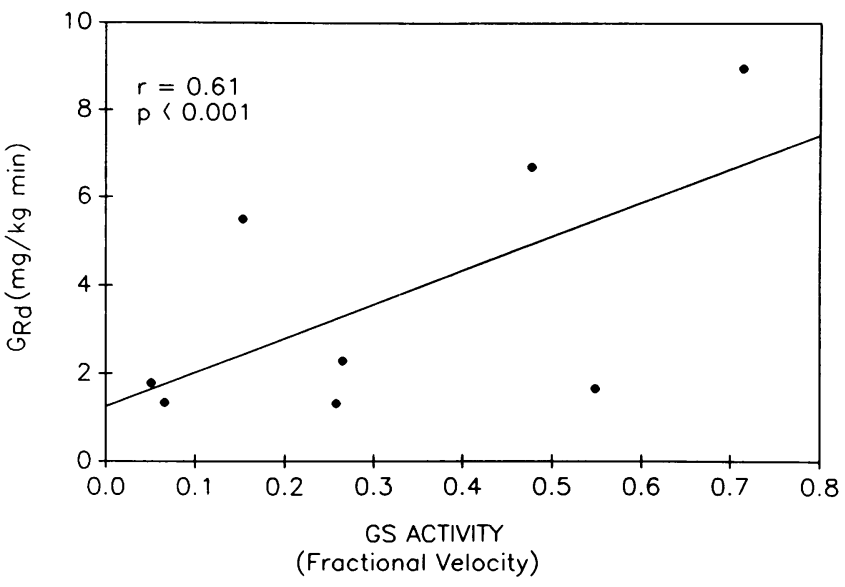

Figure 6. Correlation between GS activity (fractional velocity) and $\mathrm{G}_{\mathrm{Rd}}$. Data from studies 1 and 2.

\section{Discussion}

Effect of lipid on FAT OX and CHO OX. Lipid infusion was followed within $60 \mathrm{~min}$ by an increase in FAT OX and by a decrease in insulin-stimulated total body CHO OX (study 1). This effect was reversed, also within $1 \mathrm{~h}$, after FAT OX had declined after replacement of insulin/lipid infusion by insulin/ saline (study 3).

These observations confirm and expand reports by others which, while not specifically investigating time/effect relationships, did show that fat infusion increased total body FAT OX and decreased insulin-stimulated CHO OX within the usual 2 -h studies (10-17). Thus, there is convincing evidence demonstrating that elevation FAT OX leads to a prompt decrease in insulin-stimulated $\mathrm{CHO} O \mathrm{OX}$ in vivo. These findings are compatible with that part of Randle's glucose-fatty acid cycle hypothesis which postulated that rising plasma FFA concentrations increased FAT OX and inhibited CHO OX in striated muscle via a rise in the mitochondrial acetyl-CoA/CoA ratio and inhibition of pyruvate dehydrogenase. In further support of this hypothesis, we have demonstrated in this study that lipid infusions produced large increments in acetyl-CoA $(+432 \%)$ and in the acetyl-CoA/free CoA-SH ratio $(+489 \%)$ in human skeletal muscle.

Effect of lipid on $G_{R d}$. Randle's hypothesis, however, also postulated that increased FAT OX caused muscle citrate and G-6-P concentrations to rise (the latter by inhibition of phosphofructokinase 1) and glucose uptake to fall (by inhibition of hexokinase). In this study, we found that lipid induced increments in FAT OX did neither increase citrate nor G-6-P concentrations in muscle and did not reduce $G_{R d}\left(G_{R d}\right.$ is equivalent with glucose uptake) for at least $3 \mathrm{~h}$. On the other hand, once established, the inhibition of $G_{R d}$ lasted for several hours even after FAT OX had fallen (in study 3 ). It must be pointed out, however, that the validity of our $G_{R d}$ values depended on the accuracy of the glucose turnover measurements. As mentioned (see Methods) the stable isotope method used underestimated $G_{R a}$ (and thus $G_{R d}$ ) during hyperinsulinemia. The error, however, appeared to be relatively minor (negative values for hepatic glucose output ranged from 0.5 to $1.0 \mathrm{mg} / \mathrm{kg} \cdot \mathrm{min}$ ). Moreover, the error was similar in all three studies and thus did not invalidate our observation that lipid inhibited $\mathrm{CHO}$ OX 
first and $G_{R d}$ hours later. The long delay between the rise in FAT OX and the inhibition of $G_{R d}$, the lack of correlation between FAT OX and $G_{R d}$ and the lack of increases in muscle citrate and G-6-P concentrations cannot easily be explained by the Randle hypothesis and suggest that the effects of fat on rat heart muscle are different from those on human striated muscle. Others have arrived at similar conclusions. Lillioja et al. (37), studying lipid turnover in nondiabetic Pima Indian women during hyperinsulinemic clamps, concluded that the Randle cycle was probably operative for the regulation of $\mathrm{CHO}$ OX but not for the regulation of the nonoxidative component of $G_{R d}$. Yki-Yarvinnen et al. (38) found that the rate-limiting step for $G_{R d}$ during hyperinsulinemia appeared to be beyond the glucose transport step.

What caused the late decrease in $G_{R d}$ ? We found that $\mathrm{G}_{\mathrm{Rd}}$ correlated poorly with FAT OX and CHO OX but closely with GS activity. GS activity is generally considered to be the ratelimiting step in glycogen synthesis (39), which has recently been demonstrated to account for nearly all of $\mathrm{CHO}$ storage during euglycemic hyperinsulinemia (40). It appeared, therefore, that $G_{R d}$ declined eventually because of a problem with glycogen synthesis, which developed after several hours of insulin/lipid infusion.

The mechanism by which lipid inhibited GS activity was not explored. It is, however, known that as muscle glycogen stores fill up, GS activity decreases, at least partially owing to a decrease in the active form of GS (41-43). This may have occurred in our study where a marked fall in the active form of GS was seen after several hours of lipid infusion. Bjorntorp et al. (44) have estimated on the basis of forearm glucose uptake studies that at rest, when no utilization of glycogen has occurred, the uptake of glucose into human muscle was limited to $\sim 20 \mathrm{~g} / \mathrm{d}$. We have calculated that after $5 \frac{1 / 2}{\mathrm{~h}}$ of insulin/lipid infusion, i.e., at the time when $G_{R d}$ started to decrease sigificantly, $\sim 23.4 \mathrm{~g}$ of glucose had been prevented from being oxidized and presumably had been shunted for the most part into muscle glycogen formation. We would, therefore, like to propose the following hypothesis: during the initial 3-4 $\mathrm{h}$ of insulin/lipid infusion, when $\mathrm{G}_{\mathrm{Rd}}$ was normal but $\mathrm{CHO}$ OX was diminished, the glucose which entered the muscle, but could not be oxidized, was stored as glycogen. At least, we found no evidence that glucose was shunted in any substantial amount into other forms of nonoxidative glucose disposal such as lactate production or lipid synthesis (plasma lactate levels, presumably reflecting lactate production, did not change and npRQ values never exceeded 1.0). Blood lactate levels, however, may not accurately reflect lactate turnover and the possibility cannot be ruled out that there was a small accumulation of lactate in muscle or that some lactate was used for gluconeogenesis. After 4-5 h, muscle storage capacity was saturated and $G_{R d}$ had to decrease since all major pathways of glucose utilization were now blocked. There are, however, alternative pathways by which lipid could have affected $G_{R d}$. For instance, long chain acyl-CoA was likely to increase in muscle and may have inhibited GS activity. Palmityl-CoA has been shown to dissociate active tetrameric liver glycogen synthase into monomers which were unable to bind to the primer glycogen (45). Furthermore, we cannot rule out the possibility that lipids may have inhibited glucose transport directly. Hissin et al. have shown that feeding of high fat/low $\mathrm{CHO}$ diets for 21 days to rats reduced the number of glucose transporters in adipocytes plasma membranes and decreased glucose transport (46). Clearly, fur- ther studies are needed to determine which of these mechanisms was operative.

The delayed inhibitory effect of lipid infusion on $G_{R d}$ may explain why the in vitro studies (4-7), which were short, lasting only from 45 to $150 \mathrm{~min}$, failed to show lipid effects on glucose uptake. In addition, it may help to reconcile several contradictory in vivo reports. For instance, several groups have failed to detect effects of lipid infusions on glucose uptake during hyperinsulinemic clamps $(12,14,15,17)$, while others have found only marginal $(-15 \%)$ inhibition (10). All these studies lasted for only $2 \mathrm{~h}$. According to our data, $2 \mathrm{~h}$ is not sufficient for the inhibitory effect of FAT OX on $\mathrm{G}_{\mathrm{Rd}}$ to develop. By comparison, groups who infused lipid for 3-4 h did observe inhibition of glucose uptake $(11,16)$. Bonnadonna et al. $(15)$, in the only other study on the time dependency of lipid and glucose interaction, reported that lipid infusion, when started simultaneously with the insulin clamp, resulted in inhibition of insulin-mediated glucose disposal after 3-4 h. In contrast, when the lipid infusion was started $2 \mathrm{~h}$ after commencement of the insulin clamp and continued for another $2 \mathrm{~h}$, there was no inhibition of glucose disposal. They interpreted their findings as indicating that $2 \mathrm{~h}$ of hyperinsulinemia had rendered the body relatively refractory to the action of lipid on glucose disposal. Our findings suggested that lipids infused for $4 \mathrm{~h}$ allowed sufficient time for the inhibition of glucose disposal to develop whereas lipid infused for only $2 \mathrm{~h}$ did not.

Clinical relevance. Patients with NIDDM commonly have long histories of excessive caloric intake (frequently in the form of fat), lack of physical exercise, increased plasma FFA concentrations, and increased FAT OX. Impaired CHO STOR has been recognized as one of the earliest problems (47-49). As shown in this and other studies, many of these abnormalities including impaired glycogen synthesis can be produced by fat infusion in healthy individuals. It is, therefore, likely that an excess of FFA may contribute to the insulin resistance associated with NIDDM in susceptible individuals. Of particular interest, in this respect, is a recent report by Pascoe and Storlien (50), describing development of fasting hyperglycemia in rats with mildly compromised $\beta$-cell function after being fed a high fat diet for only $1 \mathrm{wk}$.

In summary, we have shown in normal men that insulin/ lipid infusion caused prompt inhibition of $\mathrm{CHO} O \mathrm{OX}$ which was followed after several hours by a fall in $G_{R d}$. This fall in $G_{R d}$ was associated with a drastic decrease in muscle GS activity. On the basis of these observations we concluded that lipid reduced $G_{R d}$ by interfering with glycogen synthesis. Putative mechanism included inhibition of GS by saturation of glycogen storage or by long chain acyl-CoA.

\section{Acknowledgments}

We thank the nurses of the General Clinical Research Center for help with the studies, Brenda Blyler for technical help, and Constance Harris for typing the manuscript.

This study was supported by National Institutes of Health grants AG-07988 (G. Boden), DK-22122 (Y. Liang), RR-349 (General Clinical Research Center), and a grant-in-aid from the American Diabetes Association, Philadelphia affiliate (F. Jadali).

\section{References}

1. Randle, P. J., P. B. Garland, C. N. Hales, and E. A. Newsholme. 1963. The glucose fatty-acid cycle: its role in insulin sensitivity and the metabolic disturbances of diabetes mellitus. Lancet. $i: 785-789$. 
2. Hales, C. N., and P. J. Randle. 1963. Effects of low-carbohydrate diet and diabetes mellitus on plasma concentrations of glucose, non-esterified fatty acid, and insulin during oral glucose-tolerance tests. Lancet. $i: 790-794$.

3. Randle, P. J., P. B. Garland, E. A. Newsholme, and C. N. Hales. 1965. The glucose fatty acid cycle in obesity and maturity onset diabetes mellitus. Ann. N.Y. Acad. Sci. 131:324-333.

4. Schonfeld, G., and D. M. Kipnis. 1968. Effects of fatty acids on carbohydrate and fatty acid metabolism of rat diaphragm. Am. J. Physiol. 215:513-522.

5. Cassens, R. G., R. M. Bocek, and C. H. Beatty. 1969. Effect of octanoate on carbohydrate metabolism in red and white muscle of the rhesus monkey. Am. J. Physiol. 715-719.

6. Beatty, C. H., and R. M. Bocek. 1971. Interrelation of carbohydrate and palmitate metabolism in skeletal muscle. Am. J. Physiol. 220:1928-1934.

7. Goodman, M. N., M. Berger, and N. B. Ruderman. 1974. Glucose metabolism in rat skeletal muscle at rest: effect of starvation diabetes, ketone bodies and free fatty acids. Diabetes. 23:881-888.

8. Rennie, M. J., and J. O. Holloszy. 1977. Inhibition of glucose uptake and glycogenolysis by availability of oleate in well-oxygenated perfused skeletal muscle. Biochem. J. 168:161-170.

9. Gomez, F., E. Jequier, V. Chabot, V. Buber, and J.-P. Felber. 1972. Carbohydrate and lipid oxidation in normal human subjects: its influence on glucose tolerance and insulin response to glucose. Metab. Clin. Exp. 21:381-391.

10. Ferrannini, E., E. J. Barrett, S. Bevilacqua, and R. A. DeFronzo. 1983. Effect of fatty acids on glucose production and utilization in man. J. Clin. Invest. 72:1737-1747.

11. Thiebaud, D., R. A. DeFronzo, E. Jacot, A. Golay, K. Acheson, E. Maeder, E. Jequier, and J.-P. Felber. 1982. Effect of long chain triglyceride infusion on glucose metabolism in man. Metab. Clin. Exp. 31:1128-1136.

12. Bevilacqua, S., R. Bonadonna, G. Buzzigoli, C. Boni, D. Ciociaro, F. Maccari, M. A. Giorico, and E. Ferrannini. 1987. Acute elevation of free fatty acid levels leads to hepatic insulin resistance in obese subjects. Metab. Clin. Exp. 36:502-506.

13. Lee, K. U., H. K. Lee, C. S. Koh, and H. K. Min. 1988. Artificial induction of intravascular lipolysis by lipid-heparin infusion leads to insulin resistance in man. Diabetologia. 31:285-290.

14. Wolfe, B. M., S. Klein, E. J. Peters, B. F. Schmidt, and R. R. Wolfe. 1988. Effect of elevated free fatty acids on glucose oxidation in normal humans. Metab. Clin. Exp. 37:323-329.

15. Bonadonna, R. C., K. Zych, C. Boni, E. Ferrannini, and R. A. DeFronzo. 1989. Time dependence of the interaction between lipid and glucose in humans. Am. J. Physiol. 257:E49-E56.

16. Felley, C. P., E. M. Felley, G. D. van Melle, P. Frascarolo, E. Jequier, and J.-P. Felber. 1989. Impairment of glucose disposal by infusion of triglycerides in humans: role of glycemia. Am. J. Physiol. 256:E747-E752.

17. Bevilacqua, S., G. Buzzigoli, R. Bonadonna, L. S. Brandi, M. Oleggini, C. Boni, M. Geloni, and E. Ferrannini. 1990. Operation of Randle's cycle in patients with NIDDM. Diabetes. 39:383-389.

18. DeFronzo, R. A., E. Jacot, E. Jequier, E. Maeder, J. Wahren, and J. P. Felber. 1981. The effect of insulin on the disposal of intravenous glucose: results from indirect calorimetry and hepatic and femoral venous catheterization. Diabetes. 30:1000-1007.

19. Wolfe, R. R. 1984. Tracers in metabolic research. In Radioisotope and Stable Isotope/Mass Spectrometry Methods. R. R. Wolfe, editor. Alan R. Liss, Inc., New York. 261.

20. Steele, R., J. S. Wall, R. C. DeBodo, and N. Altszuler. 1956. Measurement of size and turnover rate of body glucose pool by the isotope dilution method. Am. J. Physiol. 187:15-24.

21. Molina, J. M. A. D. Baron, S. V. Edelman, G. Brechtel, P. Wallace, and J. M. Olefsky. 1990. Use of a variable tracer infusion method to determine glucose turnover in humans. Am. J. Physiol. 258:E16-E23.

22. Owen, O. E., V. E. Trapp, G. A. Reichard Jr., M. A. Mozzoli, R. Smith and G. Boden. 1980. Effects of therapy on the nature and quantity of fuels oxidized during diabetic ketoacidosis. Diabetes. 29:365-372.

23. Tappy, L., O. E. Owen, and G. Boden. 1988. Effect of hyperinsulinemia on urea pool size and substrate oxidation rates. Diabetes. 37:1212-1216.

24. Hagg, S. A., S. I. Taylor, and N. B. Ruderman. 1976. Glucose metabolism in perfused skeletal muscle: pyruvate dehydrogenase activity in starvation, diabetes and exercise. Biochem. $J$. 158:203-210.

25. Allred, J. B., and D. G. Guy. 1969. Determination of coenzyme A and acetyl-CoA in tissue extracts. Anal. Biochem. 29:293-299.
26. Thomas, J., K. Schlender, and J. Larner. 1968. A rapid filter paper assay for UDP glucose-glycogen glucosyltransferase, including an improved biosynthesis of UDP. ${ }^{14} \mathrm{C}$-glucose. Anal. Biochem. 25:486-499.

27. Kochan, R. G., D. R. Lamb, S. A. Lutz, C. V. Perrill, E. M. Reimann, and K. K. Schlender. 1979. Glycogen synthase activation in human skeletal muscle: effects of diet and exercise. Am. J. Physiol. 236:E660-E666.

28. Lowry, O. H., and J. V. Passonneau. 1972. A Flexible System of Enzymatic Analysis. Academic Press, Inc., New York. 120-128.

29. Liang, Y., and F. M. Matschinsky. 1991. Co-enzyme A esters content in perfused islets of the rat pancreas stimulated by glucose and other fuels. Diabetes. 40:327-333.

30. Williamson, J. R., and B. E. Corkey. 1969. Assays of intermediates of the citric acid cycle and related compounds by fluorometric enzyme methods. Methods Enzymol. 13:434-513.

31. Smith, C. M., C. M. Narrow, Z. V. Kendrick, and C. Steffen. 1987. The effect of pantothenate deficiency in mice on their metabolic response to fast and exercise. Metab. Clin. Exp. 36:115-121.

32. Soeldner, J. S., and D. Slone. 1965. Critical variables in the radioimmunoassay of serum insulin using the double antibody technic. Diabetes. 14:771-779.

33. Marsh, W. H., B. Fingerhut, and H. Miller. 1965. Automated and manua direct methods for the determination of blood urea. Clin. Chem. 11:624-627.

34. Hawk, P. 1947. The Kjeldahl method. In Practical Physiology Chemistry 12th edition. Blakiston, Toronto. 814-822.

35. Hohorst, H. J. 1965. Lactate. In Methods of Enzymatic Analysis. H. U. Bergmeyer, editor. Academic Press, Inc., New York. 266

36. Bucher, T., R. Czok, W. Lampbrecht, and E. Latzkco. 1965. Pyruvate. In Methods of Enzymatic Analysis. H. U. Bergmeyer, editor. Academic Press, Inc., New York. 253.

37. Lillioja, S., C. Bogardus, D. M. Mott, A. L. Kennedy, W. C. Knowler, and B. V. Howard. 1985. Relationship between insulin-mediated glucose disposal and lipid metabolism in man. J. Clin. Invest. 75:1106-1115.

38. Yki-Jarvinen, H., A. A. Young, C. Lamkin, and J. E. Foley. 1987. Kinetics of glucose disposal in whole body and across the forearm in man. J. Clin. Invest. 79:1713-1719.

39. Leloir, L. F., J. M. Olavarria, S. H. Goldenberg, and H. Carminatti. 1959. Biosynthesis of glycogen from uridine diphosphate glucose. Arch. Biochem Biophys. 81:508-520.

40. Shulman, G. I. D. L. Rothman, T. Jue, P. Stein, R. A. DeFronzo, and R. G. Shulman. 1990. Quantitation of muscle glycogen synthesis in normal subjects and subjects with non-insulin-dependent diabetes by ${ }^{13} \mathrm{C}$ nuclear magnetic resonance spectroscopy. N. Engl. J. Med. 322:223-228.

41. Danforth, W. H. 1965. Glycogen synthetase activity in skeletal muscle. Interconversion of two forms and control of glycogen synthesis. J. Biol. Chem 240:588-593.

42. Bogardus, C., P. Thuillez, E. Ravussin, B. Vasquez, M. Narimiga, and S. Azhar. 1983. Effect of muscle glycogen depletion on in vivo insulin action in man. J. Clin. Invest. 72:1605-1610.

43. Richter, E. A. S. A. Hansen, and B. F. Hansen. 1988. Mechanisms limiting glycogen storage in muscle during prolonged insulin stimulation. Am. J. Physiol. 255:E621-E628.

44. Bjorntorp, $P$, and L. Sjostrom. 1978. Carbohydrate storage in man: speculations and some quantitative considerations. Metab. Clin. Exp. 27:1853-1865.

45. Wititsuwannakul, D., and K.-H. Kim. 1977. Mechanism of palmityl coenzyme A inhibition of liver glycogen synthase. J. Biol. Chem. 252:7812-7817.

46. Hissin, P. J., E. Karnieli, I. A. Simpson, L. B. Salans, and S. W. Cushman. 1982. A possible mechanism of insulin resistance in the rat adipose cell with high fat/low-carbohydrate feeding. Diabetes. 31:589-592.

47. Meyer, H. U., B. Curchod, E. Maeder, P. Pahud, E. Jequier, and J. P. Felber. 1980. Modifications of glucose storage and oxidation in non-obese diabetics, measured by continuous indirect calorimetry. Diabetes. 29:752-756.

48. Felber, J. P., H. U. Meyer, B. Curchod, H. U. Iselin, J. Rousselle, E. Maeder, P. Pahud, and E. Jequier. 1981. Glucose storage and oxidation in different degrees of human obesity measured by continuous indirect calorimetry. Diabetologia. 20:39-44.

49. Boden, G., T. K Ray, R. H. Smith, and O. E. Owen. 1983. Carbohydrate oxidation and storage in obese non-insulin dependent diabetic patients. Diabetes. 32:982-987.

50. Pascoe, W. S., and L. H. Storlien. 1990. Inducement by fat feeding of basal hyperglycemia in rats with abnormal $\beta$-cell function. Diabetes. 39:226-233. 